\title{
Food hygiene education in UK secondary schools: A nationwide survey of teachers' views
}

\author{
M B Egan ${ }^{b}$, Bielby $^{a}$, A Eves $^{a}$, M L Lumbers ${ }^{a}, M ~ M$ Raats $^{b}$ and M R Adams ${ }^{c}$ \\ ${ }^{a}$ Faculty of Management and Law, University of Surrey. \\ ${ }^{b}$ Faculty of Arts and Human Sciences, University of Surrey. \\ ${ }^{\mathrm{c}}$ Faculty of Health and Medical Sciences, University of Surrey.
}

\begin{abstract}
Objective A nationwide survey of teachers investigated the teaching of food hygiene in UK secondary schools. Previous studies have focused on effective strategies in consumer food hygiene training but there is little research focusing on school-based education.

Design The questionnaire was developed based on the results of indepth interviews with school teachers and included topics such as where teachers gained up-to-date food hygiene knowledge and how key food hygiene messages were reinforced.
\end{abstract}

Setting Postal questionnaires were completed by those responsible for teaching food hygiene in secondary schools.

Method Postal questionnaires were distributed to 1989 secondary schools throughout the UK (response rate 38 per cent).

Results Overall, the results indicate that teachers use a combination of methods to teach food hygiene and to reinforce food safety messages. Respondents rated demonstrations of good practice and practical activities involving young people preparing food as most effective. Teachers cited their most preferred resources for teaching food hygiene, influences on the choice of these resources, and limitations on use.

Conclusion In the UK, teachers cover food hygiene in D\&T and home economics (or equivalents in Scotland and Northern Ireland). Topics such as cooking food properly, cleanliness, storing and chilling food safely, and cross-contamination are covered, reflecting the key FSA food hygiene messages. Steps to support the teaching of food hygiene in secondary schools such as guidelines on food hygiene legislation, key topics, resources, and ideas for practical activities could help to improve young people's knowledge of food hygiene and encourage young people to spread key messages to adults.

Key words: food hygiene, secondary schools, survey, teachers, teaching resources 


\section{Introduction}

In 2004, reported cases of food poisoning in the UK totalled 70, 311 ${ }^{1}$. Epidemiological data from Europe, North America, Australia and New Zealand suggest that the home remains an important point of origin for food poisoning ${ }^{2}$ largely as a result of improper food handling by consumers ${ }^{4}$. Additional data from England, Wales and the Netherlands indicate that more than 80 per cent of Salmonella and Campylobacter infections were acquired at home ${ }^{3}$.

As the home forms a central part of the larger community and the base from which we go to all other places (the workplace, schools, to go shopping and buy food), it has a strategic position in the transmission of infection throughout the community ${ }^{5}$. Since good food hygiene in the kitchen can reduce the risk of transmission of food-borne pathogens and their toxins 6 it is essential that young people learn effective handwashing techniques and safe food handling practices.

Previous studies have focused on effective strategies in consumer food hygiene training ${ }^{7-9}$ but there is little research on school-based food hygiene education. The teaching of food hygiene in schools is one important way of getting hygiene-related information into homes, as young people can share facts about correct practice in the home setting ${ }^{10}$. During secondary education (11-16 years of age), early health-related beliefs and attitudes consolidate and dictate future behaviour11 and there is pressure for young people to do what their peers are doing in class ${ }^{12}$. If educated in an effective way, young people may act as facilitators of good food hygiene practices in the home through messages conveyed to family members, and ideally will become adults who continue to implement safe food hygiene behaviours.

In England and Wales, the teaching of food hygiene is not mandatory. However, food preparation occurs in design and technology (D\&T) lessons when pupils design and make food products ${ }^{13}$. Guidance is more explicit in Scotland and Northern Ireland, where young people study home economics. Pupils must consider hygiene and safety in food preparation and production, and employ hygienic practices when cleaning utensils and appliances in the kitchen ${ }^{14,15}$. The British Nutrition Foundation (BNF) guidelines on appropriate food and nutrition understanding for pupils recommend that 11-14 year olds should be able to plan and carry out practical tasks safely and hygienically including avoiding cross-contamination, chilling and cooking food thoroughly, and understanding the principles of food preservation ${ }^{16}$.

This nationwide survey of secondary school teachers in the UK aimed to identify the food hygienerelated topics currently taught in schools, to generate data on effective teaching and learning approaches (including preferred resources) currently used with 11-14 year olds, and to identify teachers' views on gaps in existing resources. This has resulted in recommendations for the development of new teaching resources and suggestions for additional support for teachers. Such resources and support are essential if teachers are to capitalize on this key phase when healthrelated beliefs and attitudes are developed in young people.

\section{Method}

Postal questionnaires were developed based on the results of in-depth interviews with 56 teachers ${ }^{17}$. The majority of these teachers were working in the south east of England but part of the 
sample was drawn from Wales, Northern Ireland and Scotland. This ensured that issues relevant across the UK were included. The questionnaire consisted of 18 questions and included topics such as where teachers gain knowledge of food hygiene, methods used to teach food hygiene, and how key food hygiene messages are reinforced. Teachers cited their most preferred resources for teaching food hygiene, influences on the choice of these resources, and limitations on use. Respondents also identified gaps in resources and further support needed. The questions were designed to elicit as much information as possible; this was achieved by providing a scale within the majority of questions. For example, respondents were presented with a list of methods used to teach food hygiene and asked both which methods they use and how effective the methods are using a scale from very effective to very ineffective. All questions allowed for additional free text. The questionnaire was adapted slightly to reflect curriculum differences across the UK and a pilot study assessed the clarity of the questions and instructions as well as time requirements.

In England,equal numbers of schools in each Local Education Authority $(n=154)$ were selected for the sample. This involved selecting 450 schools with high, medium and low attainment based on published Standard Assessment Tests (approx 1350 schools). Questionnaires were sent to all secondary schools in Wales $(n=230)$, half of all secondary schools in Scotland $(n=225)$ received questionnaires and all secondary schools in Northern Ireland $(n=232)$. These were distributed by post to the teacher responsible for teaching food hygiene (usually teachers of food technology or home economics) during the summer term of 2005. To increase the response rate, schools were provided with freepost return envelopes and non-respondents received a second questionnaire.

All data are presented as the mean : \pm standard error of the mean (sem). The data were analysed using the software package SPSS version 12. Data from the different geographical areas were compared using Chi-square tests. Comments added to completed questionnaires are included with the quantitative data.

\section{Results}

A total of 1989 questionnaires were sent to secondary schools throughout the UK and 759 were returned (response rate 38 per cent). For the purpose of discussion, the questionnaires from England and Wales were combined into one group, as the same curriculum is covered in both areas. Around a third ( 34 per cent) of respondents had between 5 and 20 years teaching experience and a further 59 per cent had more than

21 years. Just 7 per cent had been teaching for less than five years. Respondents were required to identify their role within the school. Thirty-three per cent identified themselves as class teachers and 64 per cent were heads of department or equivalent. Many respondents gained their knowledge through food hygiene certification (76 per cent). Other sources included common sense and personal experience (73 per cent), and initial teacher education (73 per cent). 


\section{Food hygiene in the curriculum}

Key food hygiene topics were covered in D\&T (or equivalents) with aspects of personal hygiene taught in Personal, Social and Health Education (PSHE or equivalents). Teachers were asked to identify the food hygiene topics they currently teach. Cooking food properly (97 per cent), cleanliness (94 per cent), and storing and chilling food safely (94 per cent) emerged as the three principal topics. Reheating food safely, growth of micro-organisms and cross-contamination were also covered.

\section{Methods used to teach food hygiene}

Respondents identified the approaches they used to teach food hygiene. Secondary school teachers used a range of methods to teach this topic with developing routines for safe food preparation (100 per cent), discussion of key messages (99 per cent), and demonstration of good and poor practices (99 per cent) being the most popular (see Table 1).

There were few differences between the regions apart from England and Wales making less use of internet research ( 73 per cent) but more use of microbiology experiments ( 25 per cent).

These methods were all deemed effective apart from microbiology experiments. Some small but significant differences were noted between the regions. In both Scotland and Northern Ireland internet research is seen as effective but is considered neither effective or ineffective in England and Wales $(p<0.001)$.

Teachers in England and Wales suggested that demonstrations and activities involving pupils preparing food are most effective to teach food hygiene messages. Quizzes, games, and visual materials such as videos were popular along with visits from Environmental Health Officers (EHOs), chefs and those working in the food industry. Teachers in Scotland also cited experimental work with micro-organisms and practising safe food preparation as effective methods.

Teachers reported finding peer assessment of practical activities effective in reinforcing good practice. Others in Scotland teach handwashing routines using UV light boxes, CD-ROMs, PowerPoint and interactive whiteboards. Effective methods used by teachers in Northern Ireland included showing videos of poor and good practice, taking pupils to a local college for food hygiene courses and using CD-ROMs and television programmes.

Across the UK, 14 year olds gained basic food hygiene qualifications. In Scotland, students gained the Royal Environmental Health Institute for Scotland (REHIS) Elementary Food Hygiene Certificate and in Northern Ireland resources from the Chartered Institute of Environmental Health (CIEH) were favoured.

\section{Resources used to teach food hygiene}

Respondents were asked to identify the teaching materials they use. Worksheets (100 per cent), posters (100 per cent) and textbooks (99 per cent) were the most popular. A variety of other 
teaching materials were used (see Table 2). The only regional difference to note is the more limited use of teaching packs in Northern Ireland.

Respondents in England and Wales also used basic food hygiene workbooks, teachers' packs, visits from people who work in the food industry, and demonstrations of the mishandling of food during food preparation. Those in Scotland used educational visits to agricultural shows such as The Royal Highland Show where the Food Standards Agency (FSA) has a stand and leaflets are available. Worksheets and workbooks produced in school, card games and visits to local colleges were also popular in Northern Ireland.

The most commonly used teaching materials included FSA resources (86 per cent), British Nutrition Foundation (BNF) resources ( 81 per cent) and commercial resources (79 per cent). Just 17 per cent of secondary school teachers use a school nurse to teach food hygiene messages (see Table 3 ).

\section{Limitations on teaching food hygiene}

When asked to identify any restrictions on the teaching of food hygiene, most respondents cited limited budgets and poor access to resources. Limited budgets are especially problematic when accessing expensive resources such as CD-ROMs or software requiring site licences:

Cost is fundamental; many resources are beyond our limited budget. (Respondent 525)

Access to computers is a further limitation for many teachers, with activities such as researching food hygiene on the internet or using CD-ROMs restricted for those with just one computer in the classroom. Others found school computers (without speakers) too basic for CD-ROMs using sound. Teachers with limited access to computer suites favoured low-cost resources such as worksheets.

In some schools basic equipment such as white chopping boards rather than colour-coded ones made modelling good food hygiene practice difficult. Others felt short lesson times for food preparation make it difficult for pupils to clean equipment and kitchen areas adequately. Many respondents cited the inability to do experimental work with micro-organisms:

Microbiological experiments would be effective but not possible in non-laboratory situations. (Respondent 537)

There is not enough time available to cook and clean up, washing up is sometimes rushed or unacceptable. (Respondent 475)

Teachers in all regions did not have access to laboratories and perceived it unsafe to perform experiments in food preparation areas. Other problems included finding resources such as videos to engage pupils' interest and food hygiene not being included in the national curriculum. Health and safety restrictions and lack of facilities to do microbiology in home economics were also a concern. Some felt restricted by a lack of up-to-date resources and the availability of computers. Whiteboards give teachers more scope to use software with the whole class: 
Lack of computers (only one in each home economics room) but an electronic whiteboard can be used instead of a monitor enabling a number of pupils to become involved. (Respondent 31)

Shortage of time, especially for practical activities and experimental work, within a crowded curriculum were key concerns for teachers in Northern Ireland:

Time available for practical cookery lessons when theory can be put into practice. (Respondent 225)

Lack of resources and opportunities for pupils to engage in good practice at home also restrict the teaching of food hygiene.

When asked if new materials were needed for teaching food hygiene, 82 per cent $(n=579)$ of teachers overall responded yes. Regionally this represented 76 per cent $(n=70)$ of teachers in Northern Ireland, 84 per cent $(n=89)$ in Scotland and 83 per cent $(n=420)$ in England and Wales. The three most important features in the choice of resources were rated as the accuracy of information, ease of use, and the resources being fun and interesting for young people.

Respondents made suggestions regarding the teaching materials that would help them to teach food hygiene. These included food hygiene quizzes, illustrated worksheets and ideas for practical activities. Appealing posters, pictures of microorganisms and pests, and models of micro-organisms or cards summarizing key food hygiene messages could help to gain pupils' interest. Other suggestions included fun and interesting resources such as booklets with simple facts and activities, PowerPoint presentations and interactive CD-ROMs.

Ideally, these would be freely available to schools. Many respondents identified videos as their favourite resources but recognized the presentation style quickly becomes outdated. New, low-cost versions of favourite videos would be welcomed. Activity-based resources including equipment to show examples of cross-contamination such as UV light boxes, ideas for activities and role-play were also mentioned. Those working in schools in Wales would welcome new teaching materials in the Welsh language. Teachers in all regions would like updates on new legislation and food poisoning bacteria:

Basic facts don't alter, but the emphasis sometimes does based on new findings and data. (Respondent 487)

Although many secondary school teachers gained food hygiene knowledge during teacher education, updates on developments in the field would be welcomed. Others suggested that a simplified version of the Basic Food Hygiene Certificate would motivate younger pupils.

Summaries of engaging activities with sources of support, question booklets with photocopiable word searches and puzzles which are user friendly, snakes and ladders style games, and microbiological videos or CD-ROMs to show in non-laboratory areas would be welcomed. Teachers throughout the UK would like:

- Updates on legislation

- Sets of worksheets for pupils and photocopiable puzzles 
- Appealing posters to supplement text-based resources

- Booklets, activities, PowerPoint presentations, and interactive CD-ROMs

- Updated versions of good food hygiene videos

- Access to activity-based resources and ideas

- Materials in the Welsh language

\section{Discussion}

In line with previous studies ${ }^{18,19}$, this research indicates that teachers cover elements of food hygiene in food-related subjects. Eiser et al ${ }^{18}$ reports 67 per cent of food technology teachers covering food hygiene and preparation in-depth and 31 per cent covering food poisoning with 12 to 14 year olds. Survey respondents in this research covered topics such as cooking food properly, cleanliness, storing and chilling food safely, and cross-contamination. Such topics reflect the key messages (cleaning, cooking, cooling and avoiding cross-contamination) of the FSA 4C's strategy ${ }^{6}$. Indeed, FSA resources along with BNF and Foodlink (Food and Drink Federation) resources were perceived as trustworthy. Respondents recalled young people enjoying topics relating to food hygiene and believed such knowledge was essential for young people preparing food in school. Given the risk of food poisoning in the home $e^{2,5}$, it is essential that young people learn about key food hygiene messages at school. This is especially important for young people who may not have guidance from adults at home.

The current research highlights the lack of clarity regarding topic coverage as a barrier to the effective teaching of food hygiene. Griffith and Redmond ${ }^{20}$ emphasize the importance of the teaching of food hygiene in schools, but observe that food safety has been dropped from the national curriculum. Findings indicate that teachers of 11 to 14 year olds would appreciate support in furthering and updating food hygiene knowledge. Challenges include keeping up to date with food hygiene legislation and government guidelines. Guidance on key messages, to supplement references to food hygiene in non-statutory curriculum documentation, could help to improve teacher confidence ${ }^{21}$.

Practical approaches such as demonstrations, modelling of good practice, and food preparation activities (enabling young people to develop routines) were cited as most effective. However, lack of time to engage in food preparation was identified as a further barrier to the effective teaching of food hygiene in school. Jamieson ${ }^{19}$ found food safety and hygiene were covered with 11 to 14 year olds and revisited with older pupils, but some teachers felt the teaching of practical skills inadequately supported these topics. Barriers identified by respondents in this research such as budgets, access to suitable equipment to model good practice, and lack of time, suggest these limitations remain and limit food preparation activities in schools ${ }^{22}$. Use of a particular resource may well reflect its availability or ease of access.

Griffith et al ${ }^{23}$ suggests that since food hygiene is partly knowledge-based and partly skills-based, television can be especially suited to demonstrating good hygiene skills and practices. This research found visual resources such as television programmes, videos and interactive CD-ROMs rated as effective, but access to technical equipment was cited as a limitation. There may be scope for enabling teachers to borrow expensive items such as CD-ROMs and videos from libraries. 
Respondents rated resources from organizations such as the FSA, BNF and Foodlink as effective. Eiser et $\mathrm{al}^{18}$ also found the BNF and educational publishers to be well regarded. Secondary school teachers rated accuracy of information as the most important feature of resources, so these organizations were perceived as trusted sources. Most (82 per cent) survey respondents would like new ideas for activities and resources. There is scope for the development of innovative resources and ideas for activities to engage young people in food hygiene including measures such as developing food hygiene certification to motivate pupils. Ideally, new resources would capitalize on the perceived effectiveness of activity-based teaching without ignoring the limitations associated with access to computers and budgetary constraints.

\section{Conclusion}

In the UK, teachers cover food hygiene in D\&T and home economics (or equivalents in Scotland and Northern Ireland). Topics such as cooking food properly, cleanliness, and storing and chilling food safely, and cross-contamination are covered, reflecting the key FSA food hygiene messages. Steps to support the teaching of food hygiene in secondary schools such as guidelines on food hygiene legislation, key topics, resources and ideas for practical activities could help to improve young peoples' knowledge of food hygiene and encourage young people to spread key messages to adults.

\section{Note}

In January 2008, the Department of Children, Schools and Families announced that food technology will be a compulsory Key Stage 3 curriculum entitlement for every 11 to 14-year old from September 2011. Food technology lessons will involve practical cooking lessons and classes on diet, nutrition, hygiene and healthy food shopping. These changes are likely to impact on the teaching of food hygiene in schools.

\section{Acknowledgement}

This project was undertaken as part of study B20002, Getting Food Safety and Food Hygiene Messages into Schools, funded by the UK Food Standards Agency.

\section{References}

1 Health Protection Agency. Notifications of Infectious Diseases (NOIDs). Online. Available: http://www.hpa.org.uk/infections/topics_az/noids/menu.htm (accessed June 2006).

2 Redmond EC, Griffith CJ. Consumer food handling in the home: A review of consumer food safety studies. Journal of Food Protection, 2003: 66: 130-61.

3 Scott E. Hygiene issues in the home. American Journal of Infection Control, 1999: 27: S22-25. 
4 Haysom IW, Sharp AK. Bacterial contamination of domestic kitchens over a 24-hour period. British Food Journal, 2005: 107(7): 453-66.

5 Scott E. Developing a rational approach to hygiene in the domestic setting. Journal of Infection, 2001: 43: 45-9.

6 Food Standards Agency. 4C's Strategy - Promoting Food Hygiene in the Home with a Particular Focus on Working with Schools and Promoting Local Initiatives. Online. Available: http://www.food.gov.uk/multimedia/pdfs/4cstrategydoc.pdf (accessed August 2006).

7 Rennie D. Evaluation of food hygiene education. British Food Journal, 1994: 96(11): 20-5.

8 Medeiros L, Hilliers V, Kendall P, Mason A. Evaluation of food safety education for consumers. Journal of Nutrition Education, 2001: 33(1): S27-S34.

9 Egan MB, Raats MM, Grubb SM, Eves A, Lumbers ML, Dean MS, Adams MR. A review of food safety and food hygiene training studies in the commercial sector. Food Control, 2007: 18: 1180-90.

10 Patnoad MS, Pivarnik LF. Detective Mike Robe's fantastic journey: Food safety education programmes for school-aged children. Presented at the second NSF International Conference on Food Safety, 11-13 October 2000, Savannah, GA, USA.

11 Moon AM, Mullee MA, Thompson RL, Speller V, Roderick P. Health-related research and evaluation in schools. Health Education, 1999: 1: 27-34.

12 Curtis V. Hygiene: How myths, monsters, and mothers-in-law can promote behaviour change. Journal of Infection, 2001: 43: 75-9.

13 QCA. National Curriculum Online. Online. Available: www.nc.uk (accessed June 2006).

14 Department of Education in Northern Ireland. www.deni.gov.uk (accessed July 2006).

15 Scottish Executive. Environmental Studies: Society, Science and Technology 5-14 National Guidelines. Online. Available: http://www.Itscotland.org.

uk/5to14/guidelines/environmentalstudies.asp (accessed July 2006).

16 British Nutrition Foundation (BNF). Online. Available: www.nutrition.org.uk/home. asp? siteld $=43 \&$ sectionld $=482 \&$ subSubSectionld $=477 \&$ subSectionld $=309 \&$ parentSection=300\&which=1\#1141 (accessed Sept 2006).

17 Eves A, Bielby G, Egan B, Lumbers M, Raats M, Adams M. Getting food hygiene messages into schools: Final report submitted to the Food Standards Agency in respect of project ref B20002. Unpublished Manuscript. Guildford: University of Surrey, 2005.

18 Eiser JR, Eiser C, Coulson NS. Educational priorities in food technology: A national survey of teachers' views. Health Education Journal, 1998: 57: 351-9.

19 Jamieson J. Pupils' knowledge and understanding of food hygiene. TOPIC, 2001: 26: 1-4. 
20 Griffith C, Redmond E. Evaluating hygiene behaviour in the domestic setting and the impact of hygiene education. Journal of Infection, 2001: 43: 70-4.

21 Bielby G, Egan B, Eves A, Lumbers $M$, Raats $M$, Adams M. Food hygiene education in UK primary schools: A nationwide survey of teachers' views. British Food Journal, 2006: 108(9): 721-31.

22 Ridgwell J. Food in primary schools: A research project for NATHE. Modus, 1992: 10(2): 74-6.

23 Griffith CJ, Mathias KA, Price PE. The mass media and food hygiene education. British Food Journal, 1994: 96(9): 16-21. 
TABLE 1 Methods used to teach food hygiene

\begin{tabular}{|c|c|c|c|c|c|c|c|c|}
\hline \multirow[b]{2}{*}{ Methods used to teach food hygiene } & \multirow[b]{2}{*}{$\%$} & \multirow[b]{2}{*}{$\mathbf{n}$} & \multicolumn{2}{|c|}{$\begin{array}{l}\text { England \& } \\
\text { Wales }\end{array}$} & \multicolumn{2}{|c|}{ Scotland } & \multicolumn{2}{|c|}{$\begin{array}{l}\text { Northern } \\
\text { Ireland }\end{array}$} \\
\hline & & & $\%$ & $\mathbf{n}$ & $\%$ & $\mathbf{n}$ & $\%$ & $\mathbf{n}$ \\
\hline Developing routines for safe food preparation & 100 & 702 & 100 & 510 & 100 & 105 & 100 & 87 \\
\hline Discussion of key messages & 99 & 669 & 99 & 485 & 100 & 100 & 99 & 84 \\
\hline Demonstrating good or poor practices & 99 & 694 & 99 & 505 & 100 & 104 & 99 & 85 \\
\hline Practical activities & 97 & 645 & 97 & 466 & 99 & 102 & 94 & 77 \\
\hline Making posters & 96 & 657 & 96 & 476 & 95 & 101 & 94 & 80 \\
\hline Written tasks (comprehension) & 95 & 617 & 95 & 443 & 99 & 101 & 94 & 73 \\
\hline Internet research & 76 & 461 & 73 & 243 & 87 & 78 & 83 & 62 \\
\hline Microbiology experiments & 23 & 125 & 25 & 103 & 16 & 13 & 15 & 9 \\
\hline
\end{tabular}

TABLE 2 Materials used to teach food hygiene

\begin{tabular}{|l|l|l|l|l|l|l|l|l|}
\hline & & & \multicolumn{3}{|l|}{$\begin{array}{l}\text { England \& } \\
\text { Wales }\end{array}$} & \multicolumn{2}{l|}{ Scotland } & \multicolumn{2}{l|}{$\begin{array}{l}\text { Northern } \\
\text { Ireland }\end{array}$} \\
\hline Materials used to teach food hygiene & $\mathbf{\%}$ & $\mathbf{n}$ & $\mathbf{\%}$ & $\mathbf{n}$ & $\mathbf{\%}$ & $\mathbf{n}$ & $\mathbf{\%}$ & $\mathbf{n}$ \\
\hline Worksheets & 100 & 735 & 100 & 522 & 100 & 119 & 100 & 94 \\
\hline Posters & 100 & 726 & 99 & 514 & 100 & 119 & 99 & 92 \\
\hline Textbooks & 99 & 720 & 99 & 511 & 99 & 117 & 98 & 90 \\
\hline Leaflets & 98 & 710 & 98 & 500 & 99 & 118 & 96 & 90 \\
\hline Videos & 98 & 704 & 98 & 496 & 100 & 119 & 97 & 87 \\
\hline Websites & 95 & 637 & 94 & 444 & 94 & 102 & 97 & 88 \\
\hline CD ROMS & 91 & 571 & 89 & 402 & 92 & 96 & 97 & 64 \\
\hline Teaching packs & 88 & 565 & 87 & 400 & 94 & 97 & 75 & 58 \\
\hline
\end{tabular}

TABLE 3 Use of other resources to teach food hygiene

\begin{tabular}{|c|c|c|c|c|c|c|c|c|}
\hline \multirow[b]{2}{*}{ Use of other resources to teach food hygiene } & \multirow[b]{2}{*}{$\%$} & \multirow[b]{2}{*}{$\mathbf{n}$} & \multicolumn{2}{|c|}{$\begin{array}{l}\text { England \& } \\
\text { Wales }\end{array}$} & \multicolumn{2}{|c|}{ Scotland } & \multicolumn{2}{|c|}{$\begin{array}{l}\text { Northern } \\
\text { Ireland }\end{array}$} \\
\hline & & & $\%$ & $\mathbf{n}$ & $\%$ & $\mathbf{n}$ & $\%$ & $\mathbf{n}$ \\
\hline FSA resources & 86 & 596 & 83 & 412 & 94 & 110 & 88 & 74 \\
\hline BNF resources & 81 & 545 & 79 & 379 & 86 & 94 & 87 & 72 \\
\hline Commercial resources & 79 & 519 & 79 & 370 & 83 & 88 & 75 & 61 \\
\hline FDF (Foodlink) resources & 60 & 374 & 57 & 250 & 74 & 78 & 65 & 46 \\
\hline QCA/AQA/CCEA schemes of work & 40 & 243 & 41 & 179 & 5 & 4 & 73 & 60 \\
\hline Visits from EHO & 36 & 228 & 30 & 137 & 55 & 57 & 45 & 34 \\
\hline Visit from school nurse & 17 & 99 & 17 & 74 & 12 & 10 & 22 & 15 \\
\hline
\end{tabular}

